Artículo original

\title{
Prioritization of lean tools using gap analysis and analytic network process [ANP]
}

Priorización de herramientas de manufactura liviana usando GAP análisis y proceso analítico en red

\section{Hung-da Wan}

University of Texas at San Antonio

hdwan@utsa.edu

\section{Aniket Mohan Sahasrabudhe}

University of Texas at San Antonio amsahasr@utsa.edu

\section{Leonardo Rivera}

Universidad Icesi Cali-Colombia leonardo@icesi.edu.co

Fecha de recepción: Octubre 18 de 2013 Fecha de aceptación: Diciembre 17 de 2013

\section{Keywords}

Lean Manufacturing, Analytic

Network Process, Analytic

Hierarchy Process, prioritized

list of lean tools.

\section{Palabras clave}

Manufactura Lean; proceso analítico en red; proceso analítico jerárquico; lista priorizada de herramientas lean.

\section{Abstract}

Decision making can be a complicated process, especially when we need to consider a large number of factors. In the case of companies implementing Lean Manufacturing, the vast variety of lean tools makes it harder to select the right tools for the right system at the right time. In this paper, a systematic approach is proposed to assist the decision making process in two steps. In the first step, a Gap Analysis is carried out to compare the current state of the system with a benchmark to identify the deficiency of performance in various categories. The second step employs the Analytic Network Process (ANP) to prioritize lean tools by evaluating the needs and urgency of improvements. We use ANP to prioritize a list of lean tools that need to be implemented urgently considering the current status of a manufacturing firm. A hypothetical case study demonstrates that the proposed decision making approach is capable in selecting lean tools that are applicable, suitable, and urgently needed according to user's inputs.

\section{Resumen}

La toma de decisiones puede ser un proceso complejo, especialmente cuando se debe considerar una gran cantidad de factores. En el caso de las compañías que usan Lean Manufacturing, la gran variedad de herramientas hace aún más complejo seleccionar: la herramienta correcta, para el sistema correcto, en el tiempo correcto. Este artículo propone un enfoque sistemático de apoyo el proceso de toma de decisiones, en dos pasos: en el primero, se lleva a cabo un análisis Gap, con el fin de comparar el estado actual de un sistema con una benchmark, y así identificar deficiencias en el desempeño en varias categorías; en el segundo paso, empleando el concepto de Análisis y proceso analítico en red [ANP], se priorizan herramientas lean en la evaluación de las necesidades y la determinación del nivel de urgencia de las mejoras. Usando ANP se establecen prioridades en una lista de herramientas lean, cuya implementación ser requiere con urgencia, considerando el estado actual de una empresa manufacturera. Un caso de estudio hipotético se utiliza para demostrar que el enfoque propuesto es capaz de seleccionar las herramientas que son aplicables y sostenibles, y a la vez responden a una necesidad urgente, de acuerdo con el input provisto por los usuarios. 


\section{Introduction}

The implementation of lean methodologies has shown a significant improvement in the terms of increasing efficiency, reducing the total cost of production and reducing the wastes observed in processes. In order to achieve a lean environment in industry, a large number of Lean Tools were developed such as Value Stream Mapping [VSM], Line Balancing, 5S, Kaizen and others. All these lean tools have their own capabilities and limitations. Some lean tools having a similar objective can provide good results, and we are always in search for tools that give fast results. It has been observed that in order to achieve leanness, many companies apply lean tools without a thorough analysis and end up spending large amounts money, time and effort for little gain. Applying lean tools incorrectly results in a waste of an organization's time and money, as well as reduced confidence by employees in lean techniques and philosophy (Marvel \& Standridge, 2009). It is a misconception that one lean tool is the solution to every problem; therefore similar mistakes are repeated without achieving many results.

This paper focuses on the development of based on an ANP [Analytic Network Process] model. We tested the proposed approach with a manufacturing company that wishes to remain anonymous. Based on its current situation the areas requiring immediate attention are identified and suitable lean tools are suggested. The critical aspects are followed with performance metrics. Finally, we will provide a prioritized list of lean tools which needs to be implemented in order to reach the desired benchmark.

\section{Background}

\section{A. Lean manufacturing}

The concept of Lean Manufacturing is the result of the problems faced by Japanese manufacturers after World War II. There were many problems such as shortage of material, human resources and many economies sunk into deficit as a result of the war. All these reasons forced the Japanese leaders to think towards improving their methods in manufacturing. The great Japanese leaders like Kiichiro Toyoda, Shigeo Shingo and Taiichi Ohno devised an altogether new, disciplined process-oriented system which was known as Toyota Production System or later Lean Manufacturing (Abdullah, 2003).

Knowing the success stories of the Japanese made the American leaders to actually visit Japan and learn their techniques and style of manufacturing. Thus the concept was further extended in many ways and now we know it as Lean Manufacturing. The core objective of lean manufacturing is to add value to a product by minimizing the resources required. This idea was later adapted in the US because the Japanese companies produced and distributed products with half or less human effort, capital 
investment, floor space, tools, materials, time and overall expenses (Womack, Jones \& Ross, 1990).

The philosophy that the Japanese people follow of doing business is somewhat different than that followed by the Americans. The traditional belief in the west was that the only way to make profit was to add it on top of the manufacturing cost in order to determine the selling price (Ohno, 1998). The Japanese approach believes that the customers are the generators of the selling price. The more quality one builds into the product and the more service one offers, the higher the price the customer will pay. The difference between this price and the cost of the product is what determines the profit (Ohno, 1998). The term lean indicates that the system should use less inputs than mass-production systems to deliver the same output. It also aims at increasing customer satisfaction by providing a variety of products. This business strategy has led to the evolution of different terms such as Agile Manufacturing, Just-In-Time, World Class Manufacturing etc. these all different terms more or less run parallel with lean manufacturing. Lean itself means less. So this is applicable towards reducing most of the resources of manufacturing such as cost, time, material and other resources. This is achieved by identifying and reducing wastes observed in the process. The Japanese call waste 'Muda'.

Should the reader be interested in the implementation process, in details of the lean tools and the results achieved by companies in industries, there are ample resources in the literature that cover these topics in detail (Rivera, 2008; Womack and Jones, 1996; Womack, 2002; Liker and Convis, 2011 ; Nicholas, 2010).

\section{B. Analytic Network Process [ANP]}

AHP [Analytic Hierarchy Process] was proposed by Saaty (1980) as a method of solving socio-economic decision making problems and has been used to solve a wide range of problems. AHP requires the decision maker to provide judgments about the relative importance of each criterion and then specify a preference for each decision alternative using each criterion (Gungor, 2005). The output that AHP generates is a prioritized ranking of the alternatives based on the overall preferences expressed by the decision maker or the end customer. However, many decision problems cannot be structured hierarchically because they involve the interaction and dependence of higherlevel elements on a lower level element (Saaty, 1996). Structuring a problem involving functional dependence allows for feedback among clusters of decision elements, thus they can be arranged in form of a network showing one-to-one dependency of cluster elements. Saaty suggested the use of Analytic Network Process [ANP] to solve the problem of dependence among alternatives. ANP can be used as an effective tool in cases in which the interactions among the elements of a system form a network structure. ANP replaces hierarchies with networks, in which the relationships between levels are not easily represented as higher or lower, dominated, or being dominated directly or indirectly (Saaty, 1996). 
The ANP is more of a generalization of the AHP. The feedback structure has cycles connecting its components which are not described in levels. It also has loops which states that somehow the component is connected to itself. A source node denotes an origin of paths of importance. A sink node is a destination of paths of importance. A full network can include source nodes; intermediate nodes that fall on paths from source nodes, lie on cycles, or fall on paths to sink nodes; and finally sink nodes (Saaty, 1996). Some networks can contain only source and sink nodes. Still others can include only source and cycle nodes or cycle and sink nodes or only cycle nodes (Figure 2). The main challenge that is observed in the formulation of such a model is to determine the priorities of the elements in the network and also the alternatives of the decision. Because feedback involves cycles, and cycling is an infinite process, the operations needed to derive the priorities become more demanding than has been familiar with hierarchies (Saaty, 1996).

\section{The fundamental scale}

To make a comparison between the various components in the network or hierarchy, some judgments are made in quantitative terms. Instead of simply assigning a comparison score on an arbitrary basis, a specific numerical value is assigned. Table 1 presents the fundamental scale.

Table 1. Fundamental scale for Pairwise comparison

\begin{tabular}{ll}
\hline \hline 1 & Equal Importance \\
\hline 3 & $\begin{array}{l}\text { Moderate Importance of one over } \\
\text { another }\end{array}$ \\
\hline 5 & Strong Importance \\
\hline 7 & Very Strong Importance \\
\hline $2,4,6,8$ & Extreme Importance \\
\hline Reciprocals are used for Inverse Comparisons \\
\hline \hline
\end{tabular}

The values as shown in Table 1 are assigned during the pairwise comparison in such a way that they will denote the importance of one component over the other. It is assumed that when the inverse comparison is made, the reciprocals of the respective assigned value are used. This helps in keeping the consistency of the model.

\section{Pairwise comparison and dependency}

Within the ANP network, there is sometimes dependency of one component on other. The same can be observed for the alternatives. In AHP, a hierarchy comprises of a goal, levels of elements and then the alternatives. A network has a cluster of elements and their dependencies on each other. A hierarchy can be considered as a special case of network where the connections are unidirectional considering their respective dependencies. Figures 1 and 2 give a general idea of how a hierarchy and a network will look like. 
There are two types of dependencies that are observed in either of the models: outer and inner. An outer dependency compares the influence of one component on the other. An inner dependency compares the influence of one alternative on the other within the criteria or component as described in this paper. Figures 1 and 2 both show the inner and outer dependencies of components and alternatives.

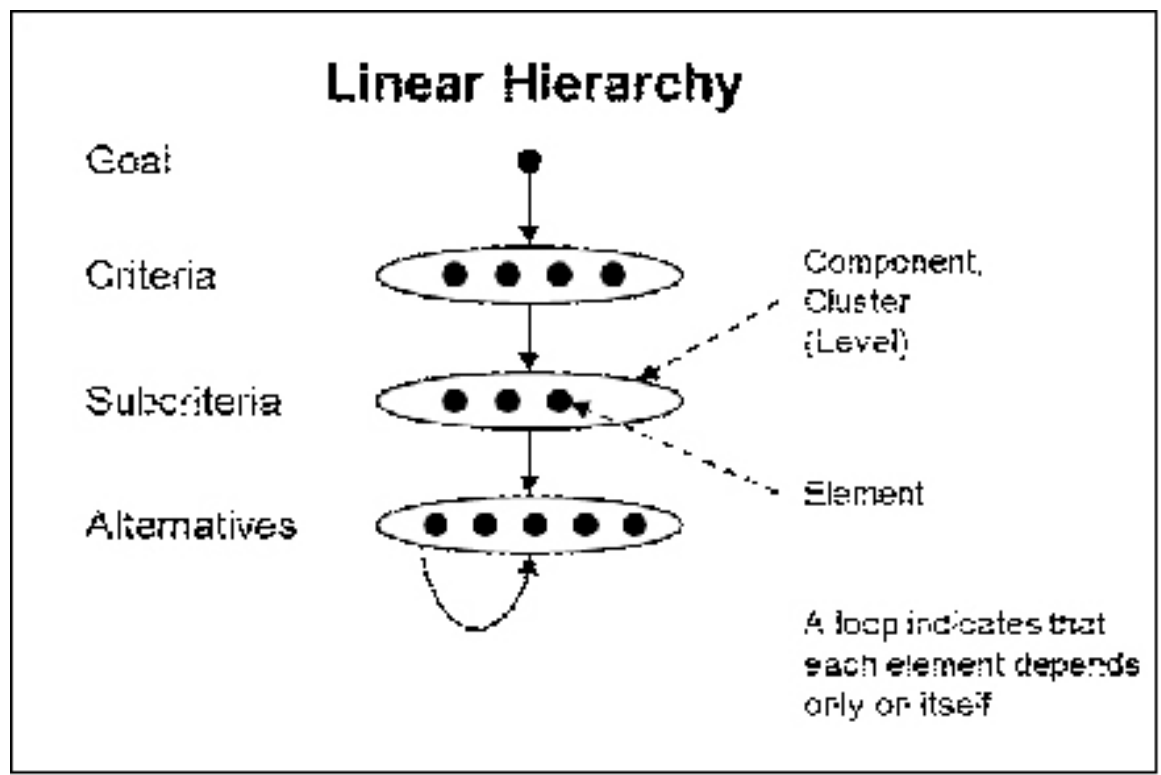

Figure 1. Linear Hierarchy model (Saaty, 1980, p.5)

\section{Feedback Network with Components having Inner and Outer Dependence among Their Elements}

A.c trom vimporemi $\mathrm{C}_{1}$ to C; incicztes tite suip depencience sit alemeriss in $\mathrm{C}_{c}$ an the elameints in $\theta_{4}$ isti respectio 3 =

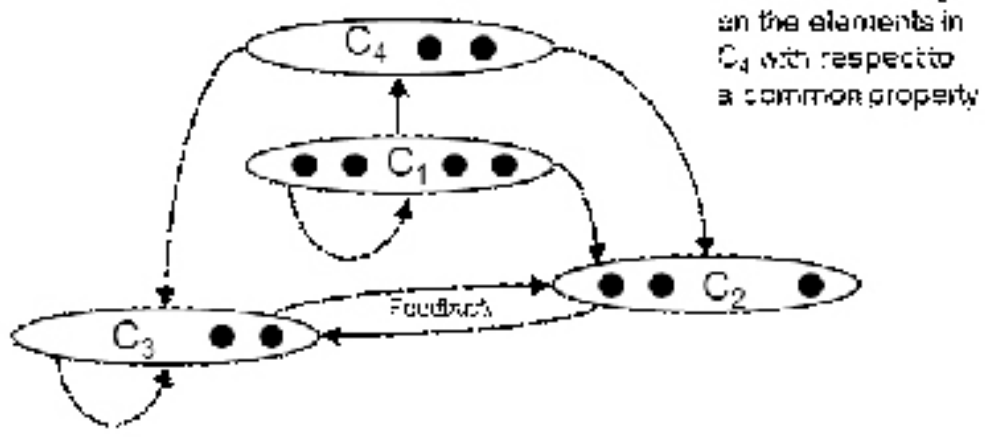

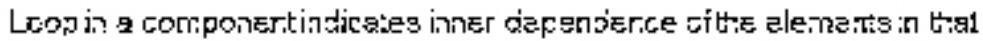
comporient with respect so a commop property'

Figure 2. Network model (Saaty, 1980, p.5) 


\section{The two-step decision model}

The two-step model we propose consists of two stages. The first one is the GAP analysis and the second is the ANP used for prioritizing the lean tools. Figure 3 shows the flow chart of the two-step model.

In the first stage, performance metrics are evaluated on the basis of urgency using the GAP analysis technique. The data obtained is from the current state and the benchmark. The second stage is to introduce the ANP tool to prioritize the lean tools. The information obtained from the two stages when combined in a proper way will give the required prioritized list of lean tools.

\section{A. GAP analysis}

GAP analysis (which stands for 'Good', 'Average' and 'Poor') is a tool used to compare the actual performance with the expected or 'target' performance. The purpose of the gap analysis is to use self-study to quickly identify the most obvious gaps and then use the existing resources to fill those gaps (Gilbert, 2008). It provides a foundation for the

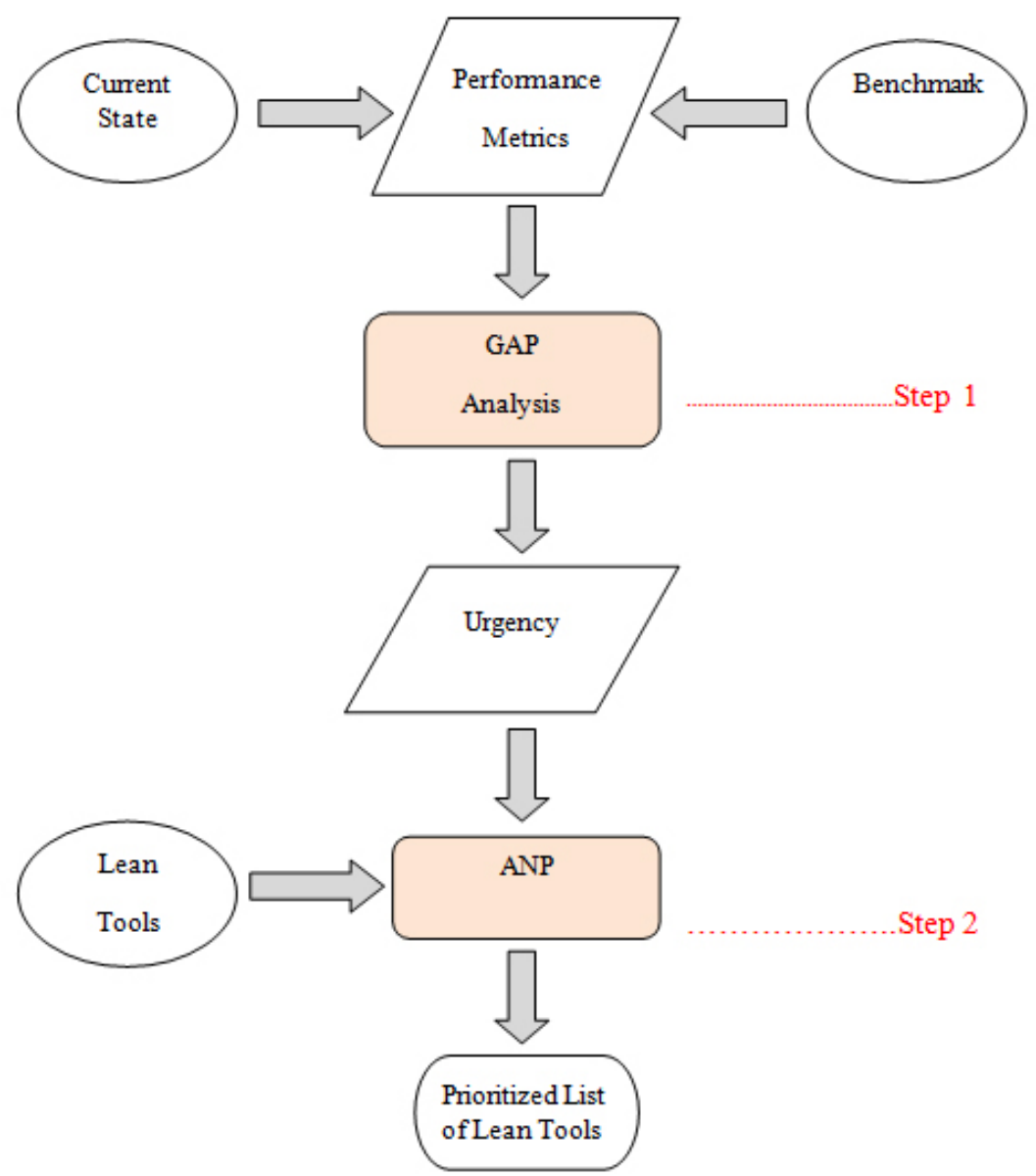

Figure 3. The two-step model 
measurement of investment done with respect to time, money and human resource. In this research, GAP analysis is done on the critical areas observed in a manufacturing firm, labeled as performance metrics. This gap in the performance is translated in terms of percentages and the term used to denote this is urgency.

The urgency can be calculated using a simple formula (Equation 1). One important thing to be noticed is the use of absolute values. The absolute values maintain the consistency of the problem.

$$
\text { Urgency }=\frac{\mid \text { Final value }- \text { Initial value } \mid}{\text { Initial value }}
$$

The ANP model proposed in this research is based on a hypothetical case. The values are assumed after a careful study considering the consistency of the model and do not relate directly to any special cases. These values are just to demonstrate the working of the model proposed.

\section{B. The ANP model}

The proposed ANP model is shown in Figure 4. The blocks denote the components showing dependency on each other. The description of the blocks is as follows.

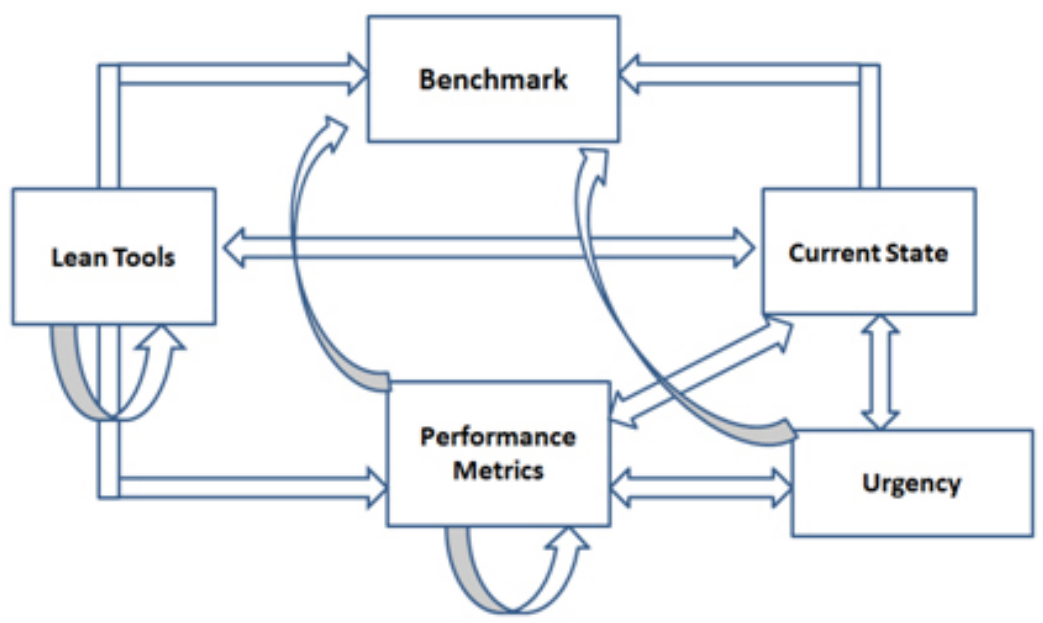

Figure 4. The ANP model

Lean Tools: This block contains the list of lean tools that needs to be ranked by their priority.

Performance Metrics: These denote the critical areas where the firm needs to focus its attention. They highlight the performance of the firm.

Current State: It denotes the current situation of the firm with respect to the identified performance metrics.

Benchmark: It is the target that the firm aims to achieve. 
Urgency: This describes the level of Importance of the performance metrics over each other.

The output of the model will be a prioritized list of lean tools for every performance metrics as well as for the whole scenario.

\section{Example case study}

The hypothetical case considered in the example below will demonstrate the working of the proposed two-step model. The Table 2 shows four main critical areas of the performance metrics that the manufacturing firm needs to work upon.

Table 2. Hypothetical case

\begin{tabular}{llll}
\hline Performance Metrics & Current State & Benchmark & Urgency (\%) \\
\hline Lead Time & 30 days & 23 days & 23.33 \\
\hline Safety & $\begin{array}{l}7 \text { incidents per } \\
\text { quarter }\end{array}$ & $\begin{array}{l}5 \text { incidents per } \\
\text { quarter }\end{array}$ & 28.57 \\
\hline Utilization & $72 \%$ & $85 \%$ & 18.06 \\
\hline Quality & $80 \%$ & $95 \%$ & 18.75 \\
\hline
\end{tabular}

The component of urgency plays an important part in determining the degree of seriousness. There might be cases where a certain area exceeds others by a significant margin. Then it is logical that one can make a decision of directing all the efforts to improving that area first.

The next step is performing the pairwise comparison of those components that have a direct influence on each other. In this paper we perform a pairwise comparison between Performance Metrics and Lean Tools.

The pairwise comparison of the lean tools is for each of the performance metrics defined in the problem. The significance of performing it was to obtain a cumulative value for each alternative. The alternatives are the lean tools to be applied. Tables 3 to 7 show the pairwise comparison made assigning the proper importance scale. The values from the fundamental scale (Table 1) are used.

Table 3. Pairwise comparison of the performance metrics

\begin{tabular}{llcll}
\hline PM's & Lead Time & Safety & Utilization & Quality \\
\hline \hline Lead Time & 1 & $1 / 2$ & 3 & 2 \\
\hline Safety & 2 & 1 & 4 & 3 \\
\hline Utilization & $1 / 3$ & $1 / 4$ & 1 & 1 \\
\hline Quality & $1 / 2$ & $1 / 3$ & 1 & 1 \\
\hline Sum & 3.83 & 2.08 & 9 & 7 \\
\hline
\end{tabular}




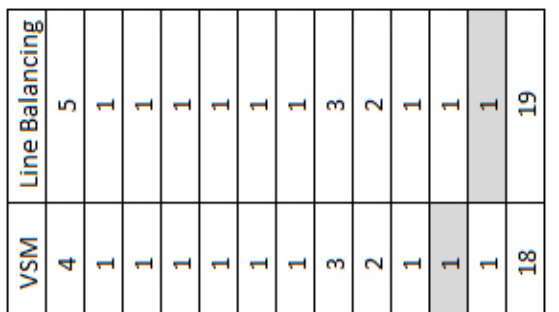

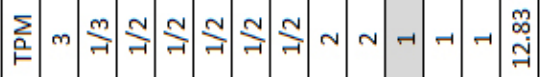

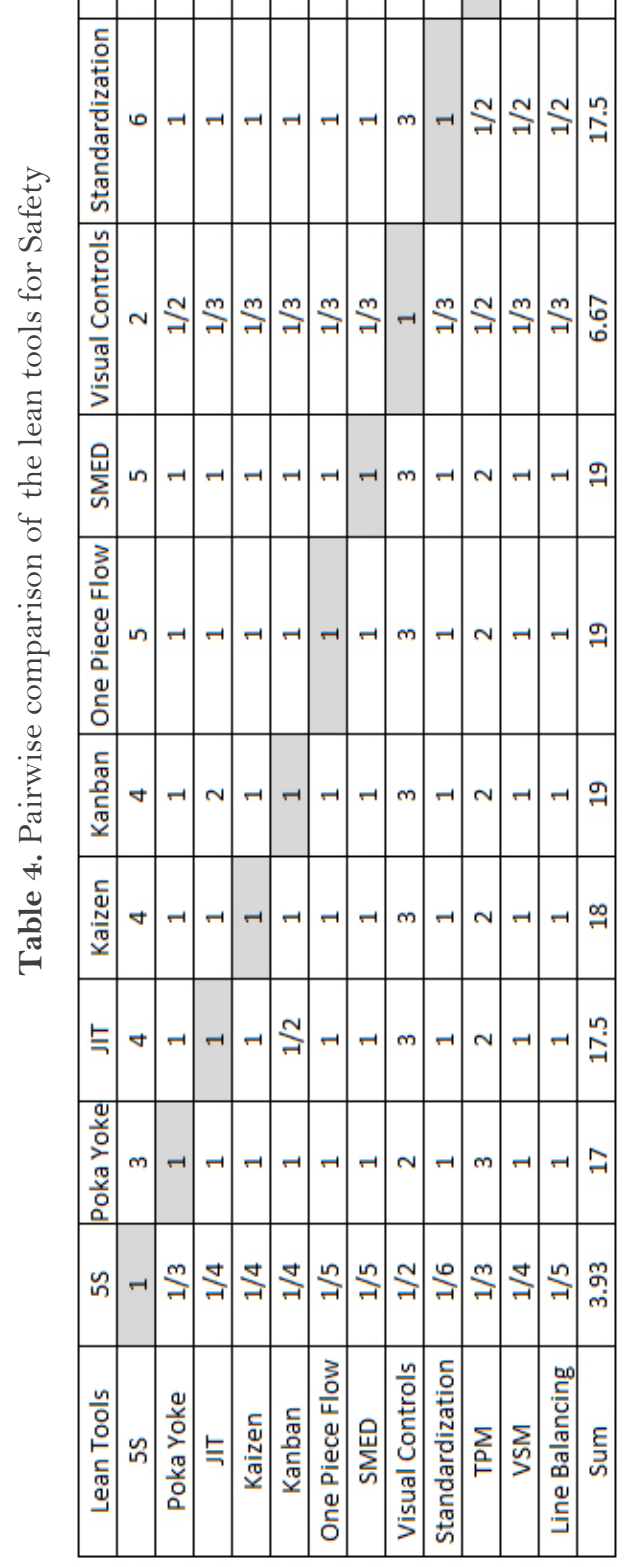

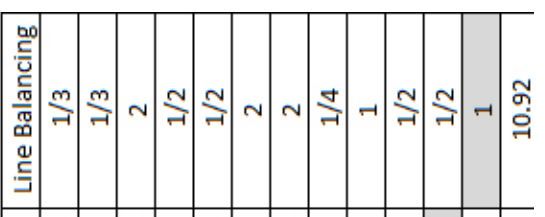

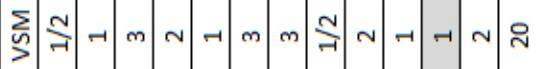

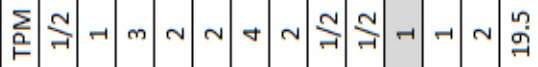

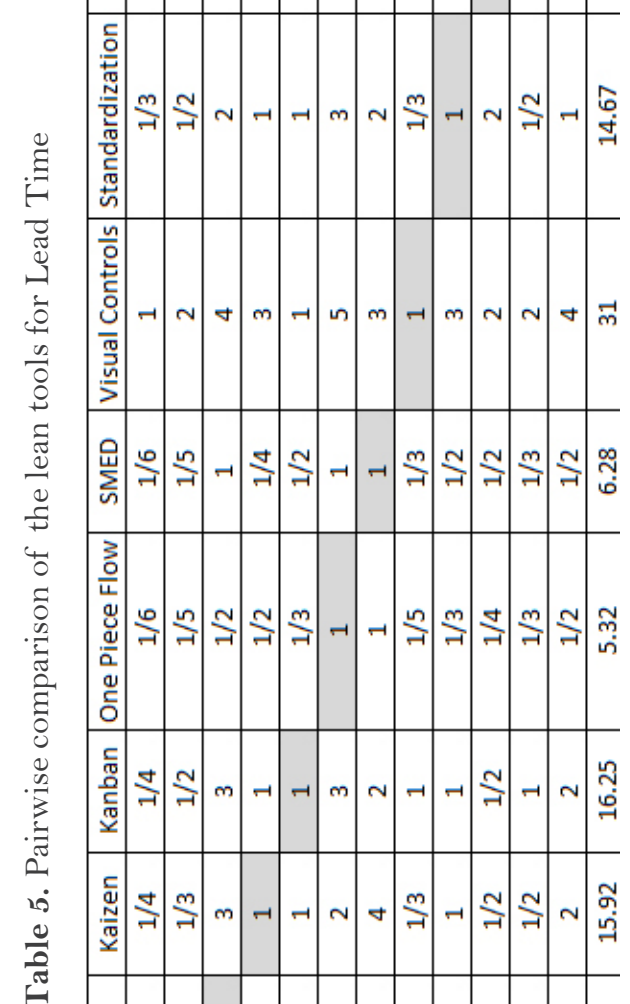

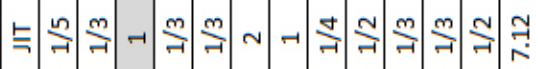

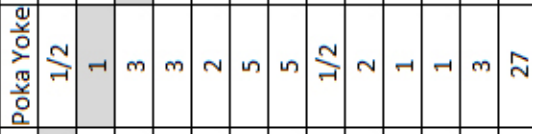
แึ.

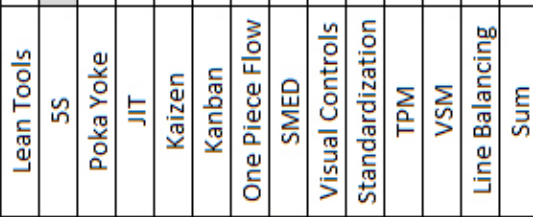




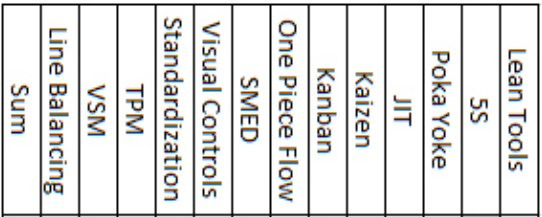

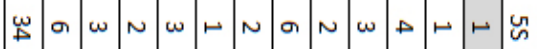

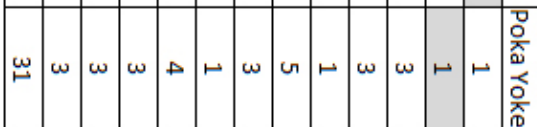

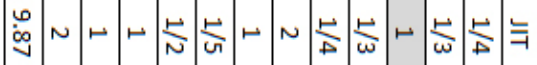

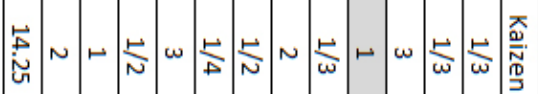

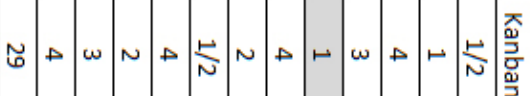

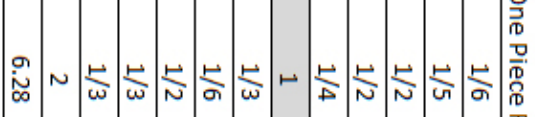

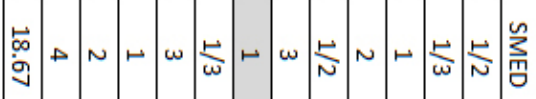

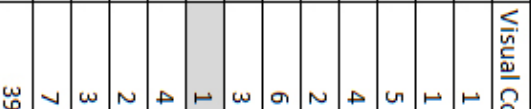

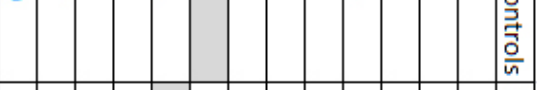

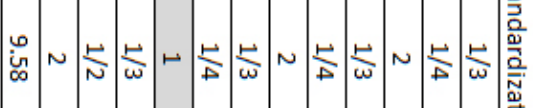

을

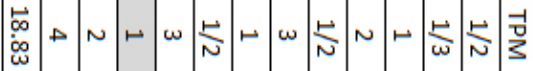

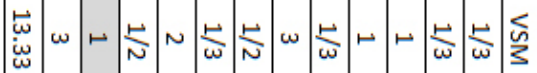

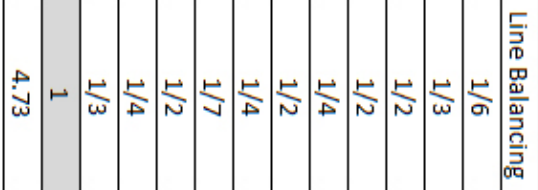

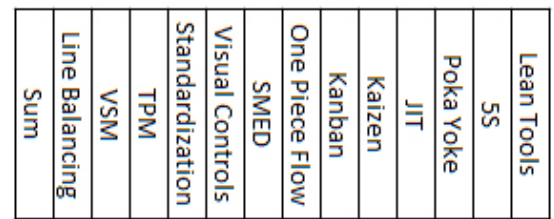

m.r.

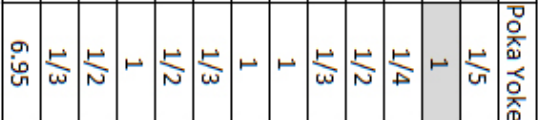

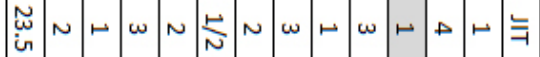

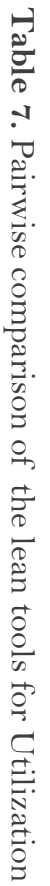

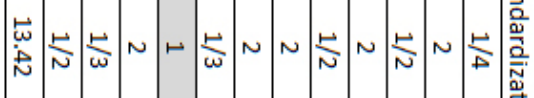

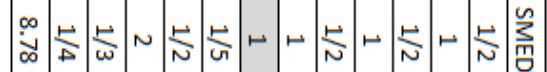

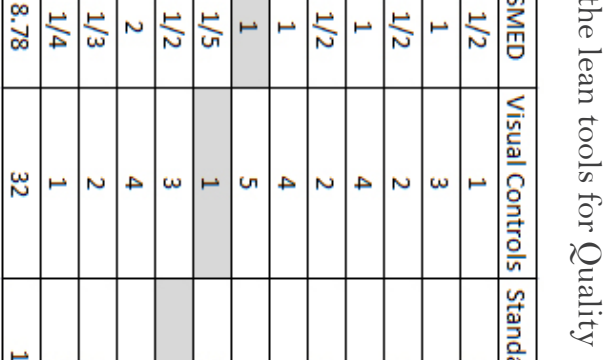

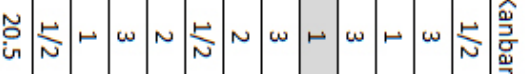

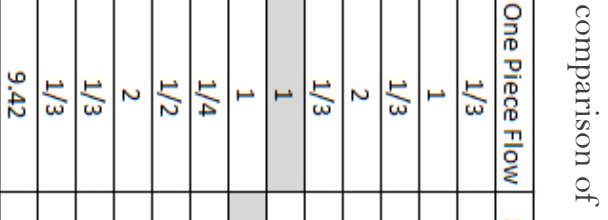

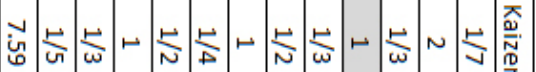

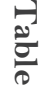

?

苛.

s.

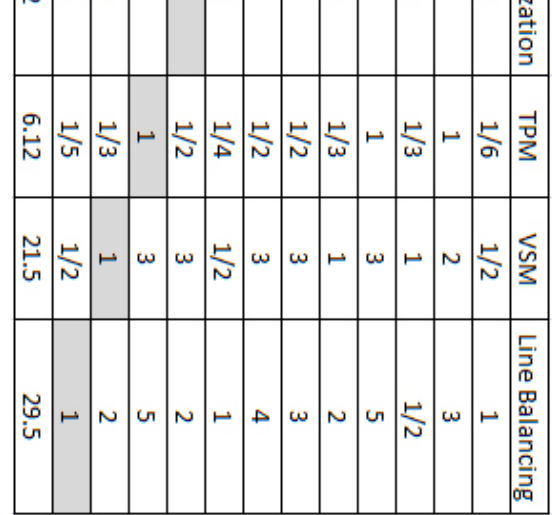


Once the proper values are inserted into the table, the sum of the respective columns is found. This gives the numeric value of the importance of one lean tool over other. The next step is to do the matrix multiplication. This is done to obtain a normalized matrix. The matrix multiplication yields an Eigenvalue for each of the components and alternatives. The matrix multiplication is carried out a number of times equal to the number of components/alternatives under consideration. It is denoted as ' $n$ '. The Eigen value that corresponds to $(n-1)^{\text {th }}$ iteration is considered. The next step is to find out the prioritized matrix by taking the values of the sum of rows as the weights of the corresponding lean tool and taking an average of those weights to get the normalized matrix.

Then we calculate the Lambda $(\lambda)$ values, which are the product of the Eigenvalue and the sum of weights for the respective lean tools.

The principal Eigenvector is the sum of all the lambda values that we have obtained. This term will determine the consistency of the matrix in the model.

Next, we check for the consistency of the matrix. This is to know if the weights that have been considered are consistent and relevant in their approach. Since ANP is a decision making process, it is important that the preferences between lean tools expressed are consistent. This is the purpose of the Inconsistency Index. The Inconsistency Index is a measure of deviation from consistency and the value obtained should be less than or equal to $10 \%$ of the overall result. Equation 2 shows the formula for the Inconsistency Index.

$$
\text { Inconsistency Index }=\frac{\lambda-n}{n-1}
$$

$\lambda=$ Principal Eigen Vector (sum of all the lambda values)

$\mathrm{n}=$ number of components/alternatives

Then we find the consistency of the matrix (equation 3).

$$
\text { Consistency }=\frac{\text { Inconsistency Index }}{\text { Random Index }}
$$

The Random Index (RI) is a predetermined number, given according to the 'n' value. For this paper, RI values of 0.9 and 1.53 are considered for $n$ values of 4 and 12 , respectively.

\section{Results and discussion}

We demonstrate the use of the model with calculations and results for Safety, one of the Performance metrics considered:

$$
\text { Urgency }=\frac{|5-7|}{7} * 100=28.57 \%
$$

Pairwise Comparison results are shown in Table 8.

The lambda values obtained are as shown in the Table 9. 
Table 8. Eigenvalues for Safety

\begin{tabular}{lcc}
\hline \multirow{2}{*}{ Lean Tool } & \multicolumn{2}{c}{ Principal Eigenvector } \\
\cline { 2 - 3 } & Normalized Matrix & Sixth Iteration \\
\hline \hline $5 \mathrm{~S}$ & $24.84 \%$ & $25.42 \%$ \\
\hline Poka Yoke & $5.67 \%$ & $6.31 \%$ \\
\hline JIT & $5.83 \%$ & $5.79 \%$ \\
\hline Kaizen & $5.39 \%$ & $5.51 \%$ \\
\hline Kanban & $5.16 \%$ & $5.34 \%$ \\
\hline One Piece Flow & $5.29 \%$ & $5.19 \%$ \\
\hline SMED & $5.29 \%$ & $5.19 \%$ \\
\hline Visual Controls & $15.49 \%$ & $14.88 \%$ \\
\hline Standardization & $7.09 \%$ & $6.59 \%$ \\
\hline TPM & $9.10 \%$ & $8.78 \%$ \\
\hline VSM & $5.48 \%$ & $5.66 \%$ \\
\hline Line Balancing & $5.37 \%$ & $5.34 \%$ \\
\hline Sum & $100.00 \%$ & $100.00 \%$ \\
\hline \hline
\end{tabular}

Table 9. Lambda values

\begin{tabular}{lc}
\hline \multicolumn{1}{c}{ Lean Tool } & Lambda values \\
\hline 5S & 0.9998 \\
\hline Poka yoke & 1.0720 \\
\hline JIT & 1.0135 \\
\hline Kaizen & 0.9916 \\
\hline Kanban & 1.0153 \\
\hline One piece flow & 0.9853 \\
\hline SMED & 0.9850 \\
\hline Visual controls & 0.9922 \\
\hline Standardization & 1.1537 \\
\hline TPM & 1.1267 \\
\hline VSM & 1.0193 \\
\hline Line balancing & 1.0145 \\
\hline Sum & $100.00 \%$ \\
\hline \hline
\end{tabular}

The principle Eigenvalue $=12.569$

$$
\begin{gathered}
\text { Inconsistency Index }=\frac{12.369-12}{12-1}=0.05 \\
\text { Consistency }=\frac{0.03}{1.53}=0.02
\end{gathered}
$$

The following part will provide a complete summary of all the results obtained. Table 10 shows the cumulative values obtained for the performance metrics. Tables 11 to 14 give the prioritized list of lean tools for the respective performance metrics. 
Table 10. Cumulative values for performance metrics

\begin{tabular}{ll}
\hline \multicolumn{1}{c}{$\begin{array}{c}\text { Performance } \\
\text { Metrics }\end{array}$} & Value (\%) \\
\hline Safety & $47.95 \%$ \\
\hline Quality & $14.42 \%$ \\
\hline Lead Time & $26.27 \%$ \\
\hline Utilization & $11.36 \%$ \\
\hline \hline
\end{tabular}

Table 11. Lean tools for safety (acc to priority)

\begin{tabular}{cccc}
\hline Lean Tools & Observed Value (\%) & Actual Value (\%) & Rank \\
\hline \hline 5 S & $25.42 \%$ & $12.19 \%$ & 1 \\
\hline Visual Control & $14.88 \%$ & $7.14 \%$ & 2 \\
\hline TPM & $8.78 \%$ & $4.21 \%$ & 3 \\
\hline Standardization & $6.59 \%$ & $3.16 \%$ & 4 \\
\hline Poka Yoke & $6.31 \%$ & $3.03 \%$ & 5 \\
\hline JIT & $5.79 \%$ & $2.78 \%$ & 6 \\
\hline VSM & $5.66 \%$ & $2.71 \%$ & 7 \\
\hline Kaizen & $5.51 \%$ & $2.64 \%$ & 8 \\
\hline Kanban & $5.34 \%$ & $2.56 \%$ & 9 \\
\hline Line Balancing & $5.34 \%$ & $2.56 \%$ & 10 \\
\hline One Piece Flow & $5.19 \%$ & $2.49 \%$ & 11 \\
\hline SMED & $5.19 \%$ & $2.49 \%$ & 12 \\
\hline \hline
\end{tabular}

Table 12. Lean tools for quality (acc to priority)

\begin{tabular}{cccc}
\hline Lean Tools & Observed Value (\%) & Actual Value (\%) & Rank \\
\hline TPM & $16.35 \%$ & $2.36 \%$ & 1 \\
\hline Poka Yoke & $15.22 \%$ & $2.19 \%$ & 2 \\
\hline Kaizen & $14.01 \%$ & $2.02 \%$ & 3 \\
\hline SMED & $11.71 \%$ & $1.69 \%$ & 4 \\
\hline One Piece Flow & $11.08 \%$ & $1.60 \%$ & 5 \\
\hline Standardization & $7.60 \%$ & $1.10 \%$ & 6 \\
\hline VSM & $4.90 \%$ & $0.71 \%$ & 7 \\
\hline Kanban & $4.85 \%$ & $0.70 \%$ & 8 \\
\hline JIT & $4.40 \%$ & $0.63 \%$ & 9 \\
\hline Line Balancing & $3.56 \%$ & $0.51 \%$ & 10 \\
\hline Visual Control & $3.34 \%$ & $0.48 \%$ & 11 \\
\hline 5 S & $3.08 \%$ & $0.44 \%$ & 12 \\
\hline \hline
\end{tabular}


Table 13. Lean tools for lead time (acc to priority)

\begin{tabular}{cccc}
\hline Lean Tools & Observed Value (\%) & Actual Value (\%) & Rank \\
\hline \hline One Piece Flow & $19.00 \%$ & $4.99 \%$ & 1 \\
\hline SMED & $16.17 \%$ & $4.25 \%$ & 2 \\
\hline JIT & $14.39 \%$ & $3.78 \%$ & 3 \\
\hline Line Balancing & $9.25 \%$ & $2.43 \%$ & 4 \\
\hline Standardization & $7.13 \%$ & $1.87 \%$ & 5 \\
\hline Kaizen & $6.97 \%$ & $1.83 \%$ & 6 \\
\hline Kanban & $6.39 \%$ & $1.68 \%$ & 7 \\
\hline TPM & $5.71 \%$ & $1.50 \%$ & 8 \\
\hline VSM & $5.05 \%$ & $1.33 \%$ & 9 \\
\hline Poka Yoke & $3.82 \%$ & $1.00 \%$ & 10 \\
\hline Visual Control & $3.51 \%$ & $0.92 \%$ & 11 \\
\hline 5 S & $2.60 \%$ & $0.68 \%$ & 12 \\
\hline \hline
\end{tabular}

Table 14. Lean tools for Utilization (acc to priority)

\begin{tabular}{cccc}
\hline Lean Tools & Observed Value (\%) & Actual Value (\%) & Rank \\
\hline Line Balancing & $21.44 \%$ & $2.44 \%$ & 1 \\
\hline One Piece Flow & $16.17 \%$ & $1.84 \%$ & 2 \\
\hline JIT & $11.45 \%$ & $1.30 \%$ & 3 \\
\hline Standardization & $11.43 \%$ & $1.30 \%$ & 4 \\
\hline Kaizen & $7.91 \%$ & $0.90 \%$ & 5 \\
\hline VSM & $7.64 \%$ & $0.87 \%$ & 6 \\
\hline SMED & $5.68 \%$ & $0.65 \%$ & 7 \\
\hline TPM & $5.62 \%$ & $0.64 \%$ & 8 \\
\hline Poka Yoke & $3.68 \%$ & $0.42 \%$ & 9 \\
\hline Kanban & $3.58 \%$ & $0.41 \%$ & 10 \\
\hline $5 S$ & $2.88 \%$ & $0.33 \%$ & 11 \\
\hline Visual Control & $2.52 \%$ & $0.29 \%$ & 12 \\
\hline \hline
\end{tabular}

The basic objective of the project was to have a prioritized list of lean tools combined for all the critical areas discussed. Taking the sum of the weights for all the cases of the respective lean tools will provide a value which then can be ranked accordingly. Table 15 shows the list of prioritized lean tools for the whole picture. This is the end result obtained for the whole research work. 
Table 15. Prioritized lean tools

\begin{tabular}{ccc}
\hline Lean Tools & Cumulative Value (\%) & Rank \\
\hline \hline 5 S & $13.64 \%$ & 1 \\
\hline One Piece Flow & $10.91 \%$ & 2 \\
\hline SMED & $9.07 \%$ & 3 \\
\hline Visual Controls & $8.83 \%$ & 4 \\
\hline TPM & $8.71 \%$ & 5 \\
\hline JIT & $8.49 \%$ & 6 \\
\hline Line Balancing & $7.94 \%$ & 7 \\
\hline Standardization & $7.43 \%$ & 8 \\
\hline Kaizen & $7.39 \%$ & 9 \\
\hline Poka Yoke & $6.64 \%$ & 10 \\
\hline VSM & $5.62 \%$ & 11 \\
\hline Kanban & $5.35 \%$ & 12 \\
\hline \hline
\end{tabular}

\section{Conclusions}

The ANP is a simple and transparent decision making tool because small errors can be easily identified. ANP can also reveal the complexity of a particular decision. Its approach represents the interest of the decision makers and expresses judgments about the relationships among the decision criteria. It is a process that uses the information from the decision maker in a simple manner. The ANP makes pairwise comparisons between the decision factors and provides fairly good results. Being simple in its approach, the tool is widely used to address a variety of concerns regarding opportunities, risks and benefits. The model does not require strong assumptions. It can be applied to even simple decision making processes as it does not involve mathematical complexities that require specialized training.

The success of any model depends upon the validation of its results. In this research the ANP model provides a prioritized list of lean tools which may not be a perfect solution but a sensible one for the preferences expressed by the decision makers. This is because of the variations in the importance levels obtained from the user's side. The rankings obtained can vary. This is the main limitation of using ANP, thus it is important to have a good knowledge of lean tools before providing the importance levels during the pairwise comparisons.

The results obtained can be refined more using a more sophisticated method for calculating lean scores. Building a simulation model will help to visualize the process and can be an extension of the model. STT 


\section{References}

Abdullah, F. (2003). Lean manufacturing tools and techniques in the process industry with a focus on steel [Doctoral Dissertation]: University of Pittsburgh: PA

Gungor, A. (2006). Evaluation of connection types in design for disassembly (DFD) using analytic network process. Computer \& Industrial Engineering, 50(1), 35-54

Gilbert, L. (2008). GAP analysis for information technology at Sacramento State: A self-study [on line]. Retrieved from http://www.csus.edu/irt/ cio/strategicplanning/documents/ GapAnalysisForInformation Technology. pdf

Liker, J. \& Convis, G. (2011). The Toyota way to lean leadership: Achieving and sustaining excellence through leadership development. New York, NY: McGraw-Hill

Marvel, J.H. \& Standridge, C.R. (2009). A simulated-enhanced lean design process. Journal of Industrial Engineering and Management, 2(1), 90-113
Nicholas, J. (2010). Production for competitive advantage: A comprehensive guide to lean methodologies and management practices. New York, NY: Productivity

Ohno, T. (1997). Toyota production system: Beyond large-scale production. New York, NY: Productivity

Rivera, L. (2008). Justificación conceptual de un modelo de implementación de Lean Manufacturing. Heurística, 15, 91-106

Saaty, T. L. (1980). The analytic hierarchy process. New York, NY: Mcgraw-Hill

Saaty, T.L. (1996). Decision making for Leaders. Pittsburgh, PA: RWS

Womack, J.P., Jones D.T., \& Roos, D. (1990). The machine that changed the world. New York, NY: Macmillan/Rawson

Womack, J.P. \& Jones, D. (1996). Lean thinking: banish waste and create wealth in your corporation. New York, NY: Simon \& Schuster

Womack, J. (2002). Lean thinking: Where have we been and where are we going? Manufacturing Engineering, 129(3), L2-L6 


\section{Currículum vitae}

Hung-da Wan

Assistant Professor, Department of Mechanical Engineering (University of Texas at San Antonio). Received a Ph.D. in Industrial \& Systems Engineering (Manufacturing Systems Engineering Option) from Virginia Polytechnic Institute and State University, Virginia Tech (2006), a M.Sc. in Industrial Engineering (2006) and a B.S. in Mechanical Engineering (1994), both from National Taiwan University, His areas of interest are: Sustainability of manufacturing systems; Lean Manufacturing Systems: assessment, value stream mapping and engineering, performance measurement systems, simulation and training programs, lean and six sigma integration; and computer integrated manufacturing and flexible automation.

\section{Aniket Mohan Sahasrabudhe}

Master of Science in Mechanical Engineering, University of Texas at San Antonio; B.S. in Production Engineering of University of Pune (India). As a graduate student, he was a member of the Sustainable Manufacturing Systems Laboratory (SMS Lab), developed by the Mechanical Engineering Department at UTSA. His professional skills are in the following areas: lean manufacturing, six sigma, design of machine elements, production planning and scheduling, design for manufacturing and assembly, and inventory management. He is currently an Asst Project Manager at Micro-Supreme Auto Industry, an Engine Precision Parts and Gauges Manufacturing Company in India.

\section{Leonardo Rivera Cadavid}

Industrial Engineer (Universidad del Valle, 1994); Master of Science in Industrial Engineering (Georgia Institute of Technology, 1996); Ph.D in Industrial and Systems Engineering (Virginia Polytechnic Institute and State University, 2006). Former Head of the Industrial Engineering Department and Director of the Industrial Engineering Program at Universidad Icesi, where he worked from May, 1998 to January, 2014. Presently affiliated with the School of Industrial Engineering at Universidad del Valle (Cali Colombia), and their research Group Logística y Producción. 